Vol IV. No.1, September 2019, hlm. 84- 90

Available online at www.jurnal.una.ac.id/indeks/jmp

\title{
PENGARUH PENGGUNAAN MEDIA GEOGEBRA TERHADAP HASIL BELAJAR SISWA PADA MATERI GRAFIK FUNGSI TRIGONOMETRI
}

\author{
Anil Hakim Syofra \\ Universitas Asahan \\ e-mail: matematikafkipuna@gmail.com
}

\begin{abstract}
The purpose of this study was to determine the use of Geogebra media on student learning outcomes in the function graph material, trigonometry in class X Meranti private high school had a significant influence. $T$ he population in this experimental study were all grade X students in Meranti Private High School in 2018/2019 school year, sample is the experimental class X-2 class with 36 people and the control class is X-1 class with 35 people selected by cluster random sampling technique. The instrument in this study consisted of a 5-item description test and a test was tested to see the feasibility of the questions. From the results of the trial test it turns out that all the questions are valid. Before testing hypotheses, normality and homogeneity are tested first. From the test it was found that the sample came from populations that have homogeneous variance and are normally distributed. From the analysis of the data obtained the average and standard deviation of the experimental class for pre-test data 58.50 and 17.67, while for the posttest data 82.64 and 23.05. For the average value and standard deviation of the control class for the pre-test data 59.81 and 18.23 , while for the post-test data 69.81 and 11.80 . From data analysis using $\mathrm{t}$-test at a level $=0.05$ obtained $\mathrm{t}$ arithmetic $=2.941$ while $\mathrm{t}$ table $=1.997$, it turns out $\mathrm{t}$ arithmetic $>\mathrm{t}$ table, then Ho is rejected and Ha is accepted. Thus it was concluded that the use of Geogebra media on student mathematics learning outcomes in the trigonometric function graphic material is better than conventional learning only.
\end{abstract}

Keyword : Geogebra, Trigonometric functions

\begin{abstract}
Abstrak
Tujuan penelitian ini adalah untuk mengetahui penggunaan media Geogebra terhadap hasil belajar siswa pada materi grafik fungsi trigonometri di kelas X SMA Swasta Meranti memiliki pengaruh yang signifikan. Populasi dalam penelitian eksperimen ini adalah seluruh siswa kelas X di SMA swasta Meranti tahun ajaran 2018/2019, sampel penelitian yaitu kelas eksperimen adalah kelas X-2 yang berjumlah 36 orang dan kelas kontrol adalah kelas X-1 yang berjumlah 35 orang yang dipilh dengan teknik cluster random sampling. Instrument dalam penelitian ini terdiri dari tes uraian sebanyak 5 soal dan tes diuji cobakan untuk melihat kelayakan soal. Dari hasil uji coba tes tersebut ternyata diperoleh bahwa seтиa soal valid. Sebelum pengujan hipotesis, terlebih dahulu diuji normalitas dan homogenitas. Dari pengujian diperoleh bahwa sampel berasal dari populasi yang memiliki varians yang homogen dan berdistribusi normal. Dari analisis data diperoleh rata-rata dan simpangan baku kelas eksperimen untuk data pre-test 58,50 dan 17,67, sedangkan untuk data post-test 82,64 dan 23,05. Untuk ilai rata-rata dan
\end{abstract}


Vol IV. No.1, September 2019, hlm. 84- 90

Available online at www.jurnal.una.ac.id/indeks/jmp

simpangan baku kelas kontrol untuk data pre-test 59,81 dan 18,23, sedangkan untuk data post-test 69,81 dan 11,80. Dari analisis data dengan mengunakan uji-t pada taraf $\alpha=$ 0,05 diperoleh $t_{\text {hitung }}=2,941$ sedangkan $t_{\text {tabel }}=1,997$, ternyata $t_{\text {hitung }}>t_{\text {tabel }}$, maka $H_{0}$ ditolak dan $H_{a}$ diterima. Dengan demikian diperoleh kesimpulasn bahwa pengguaan media Geogebra terhadap hasil belajar matematika siswa pada materi grafik fungsi trigonometri lebih baik dari pada hanya pembelajaran secara konvensional.

Kata Kunci:Geogebra, fungsi Trigonometri

\section{PENDAHULUAN}

Matematika sudah tidak asing lagi bagi kita, matematika merupakan ratudari ilmu pengetahuan dimana materi matematika di perlukan disemua jurusanyang di pelajari oleh semua orang.Matematika selain sebagai salah satu bidangilmu dalam dunia pendidikan juga merupakan salah satu bidang studi yang sangatpenting, baik bagi peserta didik maupun bagi pengembangan bidang keilmuanyang lain.

Tujuan pembelajaran matematika menurut kurikulum 2013 (Kemendiknud, 2013) menekan pada dimensi pedagogik modern dalam pembelajaran, yaitu menggunakan pendekatan scientific (ilmiah). Dalam pembelajaran matematika kegiatan yang dilakukan agar pembelajaran bermakna yaitu mengamati, menanya, mencoba, menalar, menyaji dan mencipta.

Begitu besarnya manfaat matematika, sehinggadiharuskan mempelajarinya bahkan mulai dari tingkat pendidikan yang terendah hingga yang tertinggi sekalipun. Belajar matematika tidak hanya menggunakan buku, tapi jugabisa menggunakan alat atau media lain, seperti alat peraga atau bahkan dengankomputer. Seiring berkembangnya zaman dan tekhnologi maka belajarmatematika dengan menggunakan komputer lebih mudah dan menyenangkan.

Hal ini sejalan dengan salah satu dari enam prinsip pembelajaran matematika (NCTM, 2000: 24) mengatakan "teknologi menjadi sesuatu hal yang penting dalam pembelajaran matematika, karena teknologi sangat berpengaruh dalam meningkatkan proses pembelajaran matematika". Dari pernyataan ini menegaskan bahwa proses pembelajaran yang dilaksanakan hendaknya menggunakan teknologi. Karena dengan adanya teknologi diharapkan pembelajaran menjadi interaktif, menarik dan tidak membosankan. Selain itu juga dengan menggunakan teknologi akan membantu siswa lebih memahami konsep matematika dengan cepat.

Meskipun begitu banyak cara yang dapat kita lakukan dalam mempelajari matematika tetapi masih banyak siswa yang kesulitan dalam mempelajarinya, terutama pada materi grafik fungsi trigonomatri. Selama ini siswa selalu kesulitandalam membuat grafik, selalu ada titik-titik yang tidak sesuai pada tempatnya. Halini menyebabkan rendahnya hasil belajar siswa pada materi grafik fungsitrigonometri.

Metode yang biasa digunakan guru adalah metode konvensional. Guru hanya memberikan materi, 


\section{MATEMATICS PAEDAGOGIC}

Vol IV. No.1, September 2019, hlm. 84- 90

Available online at www.jurnal.una.ac.id/indeks/jmp

contoh soal dan tugas. Keadaan ini membuat siswamenjadi bosan dan berkurangnya keinginan untuk mengikuti pembelajaranmatematika. Selain itu peran guru sangat dominan karena yang lebih berperanaktif adalah guru. Sehingga siswa tidak bisa mengembangkan materi tersebut danmengakibatkan minat belajar matematika siswa dan pemahaman konsep belumdapat tercapai secara optimal.

Untuk mengatasi masalah tersebut, maka kita perlu mengembangkan suatu bentuk media dan alat bantu pembelajaran yang efektif agar kita mampu meningkatkan kreatifitas, motivasi dan peran aktif siswa pada pelajaran matematika, khususnya pada materi grafik fungsi trigonometri. Salah satu mediadan alat bantu pembelajaran yang dapat membantu meningkatkan kreatifitas,motivasi dan peran aktif siswa adalah media pembelajaran komputer

denganmenggunakan

GeoGebra.

Menurut Wena (2010)

pembelajaran berbasis komputer adalah pembelajaranyang menggunakan komputer sebagai alat bantu. Melalui pembelajaran ini bahanajar disajikan melalui media komputer sehingga kegiatan proses belajar mengajarmenjadi lebih menarik dan menantang bagi siswa. Dengan rancanganpembelajaran komputer yang bersifat interaktif, akan mampu meningkatkanmotivasi siswa dalam belajar.

Menurut $\begin{array}{r}\text { Hohenwarter } \\ \text { GeoGebra }\end{array}$
(2008),program
sangatbermanfaat bagi guru maupun
siswa. Bagi guru, GeoGebra
menawarkan kesempatan yang efektif
untuk mengkreasi lingkungan belajar
online interaktif yang memungkinkan
siswa mengeksplorasir berbagai
konsep-konsep ratematis.

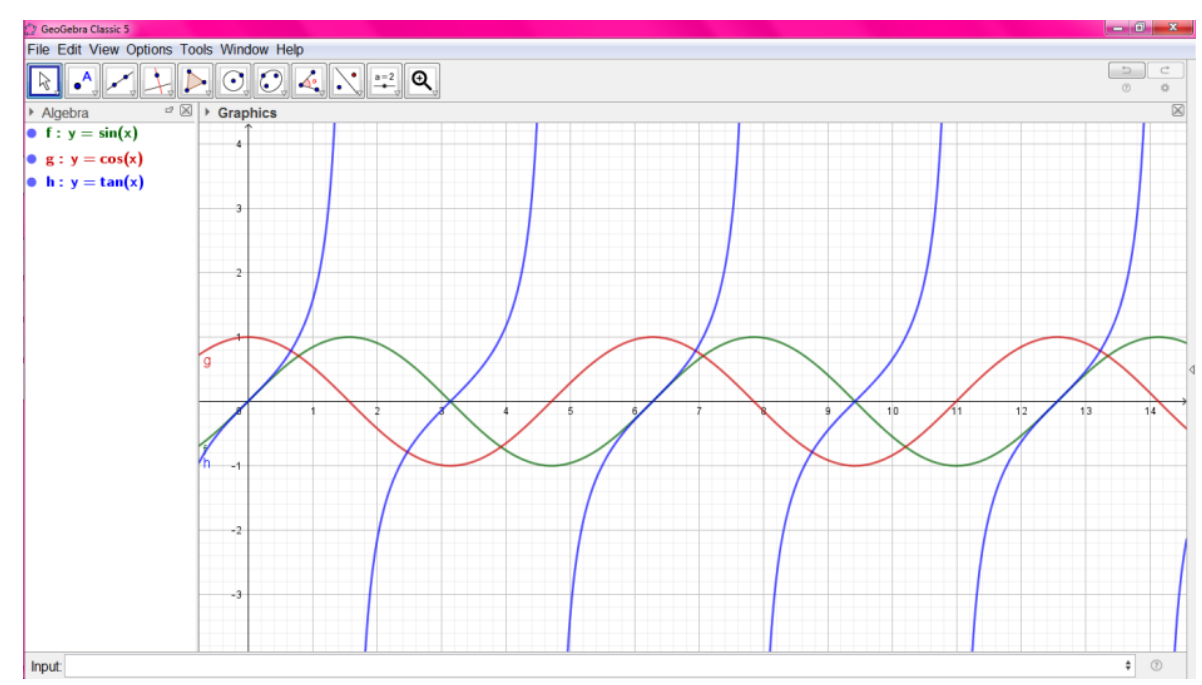

gambar 1 Grafik Fungsi Trigonometri $(y=\sin x, y=\cos x$ dan $y=\tan x)$ 
Vol IV. No.1, September 2019, hlm. 84- 90

Available online at www.jurnal.una.ac.id/indeks/jmp

\section{METODE}

Populasi dalam penelitian eksperimen ini adalah seluruh siswa kelas X di SMA Swasta Meranti tahun ajaran 2018/2019. Sedangkan yang menjadi sampel penelitian yaitu kelas eksperimen adalah kelas X-2 yang berjumlah 36 orang dan kelas kontrol adalah kelas X-1 yang berjumlah 35 orang yang dipilh dengan teknik cluster random sampling.

Instrument dalam penelitian ini terdiri dari lembar observasi untuk peserta didik dan tes uraian sebanyak 5 soal dan tes diuji cobakan untuk melihat kelayakan soal. Dari hasil uji coba tes tersebut ternyata diperoleh bahwa semua soal valid. Sebelum pengujan hipotesis, terlebih dahulu diuji normalitas dan homogenitas.

\section{HASIL DAN PEMBAHASAN \\ Data Hasil Penelitian}

Data nilai rata-rata dan standard deviasi pada pre-test dapat dilihat pada tabel berikut:

Tabel. 1 Rata-rata Kemampuan Siswa Kelas Eksperimen dan Kelas Kontrol pada data pre-test

\begin{tabular}{lcccc}
\hline \multirow{2}{*}{ Kelompok } & $\overline{\boldsymbol{X}}$ & \multicolumn{3}{c}{ Hasil Kemampuan Awal Siswa } \\
& SD & Min & Max \\
\hline Eksperimen & 58,5 & 17,67 & 33 & 86 \\
Kontrol & 59,81 & 18,23 & 33 & 86 \\
\hline
\end{tabular}

Dari Tabel. 1 dapat dilihat bahwa hasil belajar siswa untuk kelas eksperimen diperoleh nilai tertinggi 86 dan nilai terendah 33 dengan rata-rata $(\bar{X})=58,5$ dan standard deviasi $(S D)=17,67$. Sedangkan di kelas kontrol diperoleh nilai tertinggi 86 dan nilai terendah 33 dengan rata-rata $(\bar{X})=59,81$ dan standard deviasi $(S D)=18,23$.

Data nilai rata-rata dan standard deviasi pada pre-test dapat dilihat pada tabel berikut:

Tabel. 2 Rata-rata Kemampuan Siswa Kelas Eksperimen dan Kelas Kontrol pada data post-test

\begin{tabular}{lcccc}
\hline \multirow{2}{*}{ Kelompok } & \multicolumn{4}{c}{ Hasil Kemampuan Siswa } \\
\cline { 2 - 5 } & $\overline{\boldsymbol{X}}$ & SD & Min & Max \\
\hline Eksperimen & 82,64 & 23,05 & 75 & 97,5 \\
Kontrol & 69,81 & 11,80 & 50 & 87,5 \\
\hline
\end{tabular}

Dari Tabel. 2 dapat dilihat bahwa hasil belajar siswa untuk kelas eksperimen diperoleh nilai tertinggi 97,5 dan nilai terendah 75 dengan ratarata $(\bar{X})=82,64$ dan standard deviasi $(S D)=23,05$. Sedangkan di kelas kontrol diperoleh nilai tertinggi 87,5 dan nilai terendah 50 dengan rata-rata $(\bar{X})=69,81$ dan standard deviasi $(S D)=11,80$.

\section{Analisis Data}

Data uji normalitas pre-test dapat dilihat pada tabel berikut: 


\section{MATEMATICS PAEDAGOGIC}

Vol IV. No.1, September 2019, hlm. 84- 90

Available online at www.jurnal.una.ac.id/indeks/jmp

Tabel. 3 Data Uji Normalias Pre-test

\begin{tabular}{lccc}
\hline Kelompok & $\boldsymbol{x}_{\text {hitung }}$ & $\boldsymbol{x}_{\text {tabel }}$ & Status \\
\hline Eksperimen & 30,79 & 12,6 & Berdistribusi Normal \\
Kontrol & 60,59 & 12,6 & Berdistribusi Normal \\
\hline
\end{tabular}

Pengujian normalitas data dengan mengunakan uji chi-kuadrat untuk kelas eksperimen pada data pretest diperoleh $x^{2}$ hitung $=30,79$, dan $x_{\text {tabel }}^{2}=12,6$, dengan $d k=6$ dan taraf $\alpha=0,05$. Karena $x^{2}{ }_{\text {hitung }}>$ $x^{2}$ tabel maka dapat disimpulkan bahwa data pre-test berdistribusi normal. Sedangkan untuk kelas kontrol pada Tabel. 4 Data Uji Normalias Post-test

\begin{tabular}{lccc}
\hline \multicolumn{1}{c}{ Kelompok } & $\boldsymbol{x}_{\text {hitung }}$ & $\boldsymbol{x}_{\text {tabel }}$ & Status \\
\hline Eksperimen & 25,22 & 12,6 & Berdistribusi Normal \\
Kontrol & 24,72 & 12,6 & Berdistribusi Normal \\
\hline
\end{tabular}

Untuk data post-test kelas eksperimen diperoleh $x^{2}{ }_{\text {hitung }}=$ 25,22 , dan $x_{\text {tabel }}^{2}=12,6$, dengan $d k=6$ dan taraf $\alpha=0,05$. Karena $x^{2}{ }_{\text {hitung }}>x^{2}$ tabel maka dapat disimpulkan bahwa data post-test berdistribusi normal. Sedangkan untuk kelas kontrol pada data post-test diperoleh $x_{\text {hitung }}^{2}=24,72$, dan data pre-test diperoleh $x^{2}$ hitung $=$ 60,59, dan $x_{\text {tabel }}^{2}=12,6$, dengan $d k=6$ dan taraf $\alpha=0,05$. Karena $x_{\text {hitung }}^{2}>x^{2}$ tabel maka dapat disimpulkan bahwa data pre-test berdistribusi normal.

Data uji normalitas post-test dapat dilihat pada tabel berikut:

$x_{\text {tabel }}^{2}=12,6$, dengan $d k=6$ dan taraf $\alpha=0,05$. Karena $x^{2}{ }_{\text {hitung }}>$ $x^{2}{ }_{\text {tabel }}$ maka dapat disimpulkan bahwa data post-test berdistribusi normal.

Uji homogenitas kedua kelompok pada data pre-test dan posttest disajikan dalam bentuk tabel berikut:

Tabel. 5 Data Uji Homogenitas Varians Sampel

\begin{tabular}{lccl}
\multicolumn{1}{c}{ Kelompok } & $\boldsymbol{F}_{\text {hitung }}$ & $\boldsymbol{F}_{\text {tabel }}$ & Status \\
\hline Pre-test & 1,06 & 1,754 & Homogen \\
Post-test & 3,81 & 1,754 & Tidak Homogen \\
\hline
\end{tabular}

Untuk uji homogenitas digunakan uji varians terbesar banding varians terkecil untuk data pre-test diperoleh $F_{\text {hitung }}=1,06$, dan $F_{\text {tabel }}=$ 1,754 , karena $F_{\text {hitung }}<F_{\text {tabel }}$, maka dapat disimpulkan bahwa kedua kelompok memiliki varians yang homogen. Sedangkan untuk data posttest diperoleh $F_{\text {hitung }}=3,81$, dan $F_{\text {tabel }}=1,754$, karena $F_{\text {hitung }}>$ $F_{\text {tabel }}$, maka dapat disimpulkan bahwa kedua kelompok memiliki varians yang tidak homogen.

Uji hipotesis dilakukan dengan menggunakan uji $\mathrm{t}$ melalui uji satu pihak yaitu pihak kanan, dengan demikian hipotesis statistiknya adalah:

$H_{0}: \mu_{1}=\mu_{2}:$ Hasil belajar siswa pada kelas eksperimen materi grafik fungsi trigonometri dengan tanpa menggunakan media 
Vol IV. No.1, September 2019, hlm. 84- 90

Available online at www.jurnal.una.ac.id/indeks/jmp

Geogebra kurang dari atau sama dengan rata-rata hasil belajar siswa di kelas kontrol.

$H_{a}: \mu_{1}>\mu_{2}$ : Hasil belajar siswa pada kelas eksperimen materi grafik fungsi trigonometri dengan menggunakan media Geogebra lebih dari rata-rata hasil belajar siswa di kelas kontrol.

Dengan kriteria pengujian $H_{0}$ ditolak jika $t_{\text {hitung }}>t_{-}\left(\frac{1}{2} \alpha\right)\left(n_{1}+n_{2}-2\right)$

Dari hasil pengujian uji hipotesis diperoleh perhitungan $t_{\text {hitung }}=$ 2,941 dan $t_{\text {tabel }}=1,997$,dengan $d k=69$ dan taraf $\alpha=0,05$. Karena $\quad t_{\text {hitung }}>t_{\text {tabel }}$ maka $H_{0}$ ditolak, sebaliknya $H_{a}$ diterima sehingga dapat disimpulkan bahwa hipotesis dapat diterima yaitu hasil belajar siswa dengan menggunakan media Geogebra lebih baik dibandingkan dengan menggunakan pembelajaran konvensional pada materi grafik fungsi trigonometri.

\section{SIMPULAN}

Dari hasil analisis data yang dilakukan dalam penelitian ini dapat diambil kesimpulan sebagai berikut:

a. Rata-rata hasil belajar matematika siswa pada pembelajaran dengan menggunakan media Geogebra pada materi grafik fungsi trigonometri menunjukkan rata- rata 82,64 dan simpangan baku 23,05 dimana sebelumnya nilai rata-rata 58,50 dan simpangan baku 17,67.

b. Rata-rata hasil belajar matematika siswa pada pembelajaran dengan menggunakan pembelajaran konvensional pada materi grafik fungsi trigonometri menunjukkan rata-rata 69,81 dan simpangan baku 11,80 dimana sebelumnya nilai rata-rata 59,81 dan simpangan baku 18,23.

c. Dengan media Geogebra, pembelajaran grafik fungsi trigonometri lebih menyenangkan, dikarenakan siswa lebih mudah dalam menggambar dan menemukan titik-titik pada suatu fungsi trigonometri.

d. Terdapat pengaruh hasil belajar siswa yang signifikan antara kelas eksperimen (dengan media Geogebra) dan kelas kontrol (tanpa media Geogebra) pada media grafik fungsi trigonometri.

e. Hasil belajar siswa menggunakan media Geogebra lebih baik dibandingkan dengan hasil belajar siswa menggunakan pembelajaran konvensional pada materi grafik fungsi trigonometri di kelas $\mathrm{X}$ SMA Swasta Meranti Tahun Pelajaran 2018/2019. 


\section{MATEMATICS PAEDAGOGIC}

Vol IV. No.1, September 2019, hlm. 84- 90

Available online at www.jurnal.una.ac.id/indeks/jmp

\section{DAFTAR RUJUKAN}
Hohenwarter, M., et al. (2008). Teaching and Learning Calculus with FreeDynamic Matgematics Software GeoGebra. Tersedia; http://www.publications.uni.lu/ record/2718/files/ICME11 - TSG16.pdf

Kemendikbud. (2013). Kerangka Dasar dan Struktur Kurikulum 2013. Jakarta: Kemendikbud
National Council of Teachers of Mathematics. 2000. Principles and Standards for School Mathematics. VA: United States of America.

Sudjana. (2002). Metoda Statistika. Bandung: PT. Tarsito.

Wena, Made. (2010). Strategi Pembelajaran Inovative Kontenporer. Jakarta: Bumi Aksara 